\title{
Investigation of PLC for logic Selectivity Communication in Protection Systems
}

\author{
S. Boughazala Mohamed ${ }^{1}$, A. Cheriet ${ }^{1}$ and D. Ben Attous ${ }^{2}$ \\ ${ }^{I}$ Electrical Engineering Laboratory (LGEB), University of Biskra. ALGERIA \\ ${ }^{2}$ Faculty of Technology, Department of Electrical Engineering, University of El-Oued. ALGERIA \\ bougsalah@yahoo.com
}

\begin{abstract}
This paper reports an investigation of power line communication technique PLC for logic selectivity in protection systems. A simulation of power grid with two protection systems using PLC as communication process is performed by Simulink/Matlab program. Also, the attenuation characteristic of high frequency PLC signal is studied regards to resistance, inductance and frequency variation.
\end{abstract}

Keywords: Power line communication PLC, Logic selectivity, Protection, Coupler, Attenuation. Received: 25/04/2017-Accepted: 03/06/2017

\section{Nomenclature}

PLC: Power line communication.

\section{Introduction}

Selectivity between protection elements consists to isolate as quickly as possible only the defect parts and leaving under electrical power all healthy parts [1]. By the way, both service continuity of power supply and assistance function between different protection elements are ensured. When a fault occurs in a radial network, the fault current is located between the source and the fault point. Protections upstream of the fault are solicited [1]. Downstream protections of the defect are not solicited. Subsequently, only the first protection upstream of the fault must act $[2,3]$. Each circuit breaker is associated with protection able of sending and receiving a logic data as is shown in Fig. 1.

In the fact, the logic selectivity has been developed with the aim of overcoming disadvantages of both current and timed selectivity [4]. It makes possible to obtain a perfect selectivity and reduce considerably the delay in tripping the circuit-breakers closest to the source [3, 4]. Power Line Communications PLC is a technology that makes possible the transmission of voice [5], video and data over standard power lines [6, 7]. This will include the wiring systems of homes and offices. PLC system does not require civil engineering works or modification of the current power distribution lines which covering approximating all population [8]. This makes PLC a highly competitive option in term of costs and services in comparison with the current broadband solutions available.

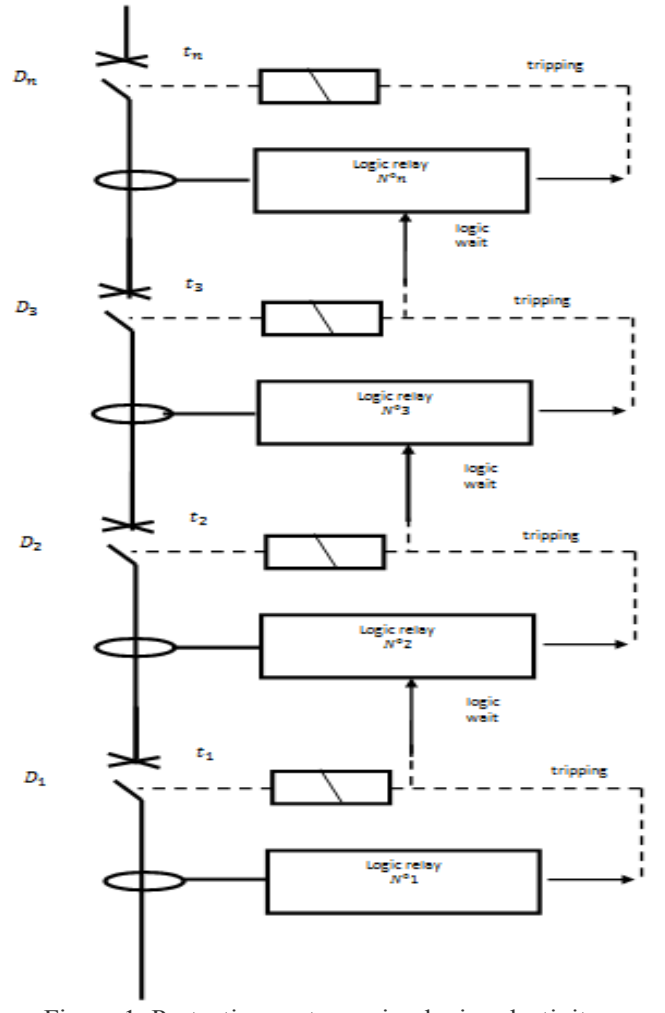

Figure 1. Protection system using logic selectivity 
PLC uses power distribution lines for the transmission of data. The electric current reaches users in the form of low-

frequency alternating current of $50 \mathrm{~Hz}$ [8]. PLC uses high-frequency carriers for data transportation. The band used covers a range between $1 \mathrm{MHz}$ and $34 \mathrm{MHz}$ [8]. In general, the PLC uses OFDM coding for data transmission [1]. This modulation is the safest against interferences taking place in power networks and provides the highest level of spectral performance and efficiency.

The principle of PLC is to superimpose the electrical signal of $50 \mathrm{~Hz}$ another signal at higher frequencies and low energy [6-9]. This second signal propagates on the electrical grid and can be received and decoded by PLC receiver which is on the same grid $[9,10]$.

In this paper the PLC technique is investigated to ensure communication between circuit-breakers. The high frequency signal is modulated by using AM modulation. Two circuit-breakers protection system is used to show the applicability of the PLC as communication way in power system protection [1-3].

\section{Topological design of the system}

A three phase line and two protection systems simulation is carried out with Simulink/Matlab Program. The simulink model is shown in Fig.2. Each protection is associated to circuit-breaker and logic relay which receiving fault information from its current transformer $\mathrm{CT}$ and emitting tripping and logic wait signals.

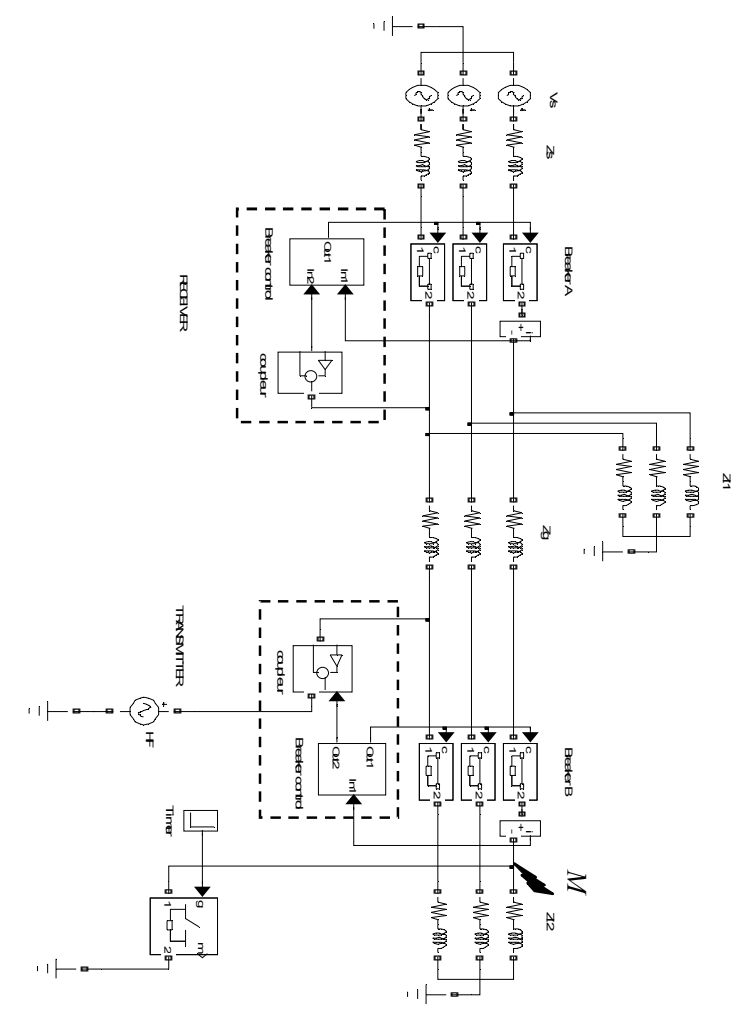

Figure 2. Simulink model of three phase network with two level protection system using logic selectivity controlled with PLC signals.

The transmitter and receiver couplers are presented in Figure 3 and Figure 4 respectively.

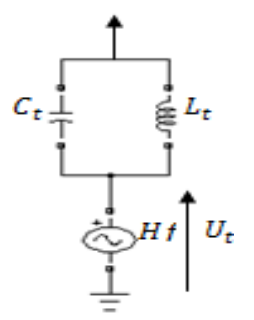

Figure 3. Transmitter coupler of PLC signals, $C_{t}=1.013 \mu \mathrm{F}, L_{t}=10^{-5} \mathrm{H}$, $f=50 K h z$.

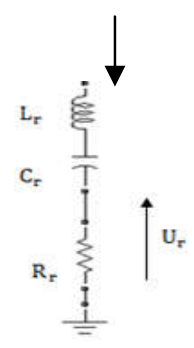

Figure 4. Receiver coupler of PLC signals, $L_{r}=10^{-4} \mathrm{H}$, $C_{r}=1.0132 \times 10^{-6} \mu F, R_{r}=15 \Omega$.

\section{Simulation results}

Case 1- Grid without faults:

The protection B is not affected; therefore the logic relay of protection $\mathrm{B}$ does not transmit a logic wait signal to the protection $\mathrm{A}$. In this case, we have a normal network operation that the current flows from the source to the load. The simulation results of this case are shown is Figure 5.

\section{Case 2- When a fault appears in point M (Figure 2):}

When a fault appears in point $\mathrm{M}$, a fault current through both protections $\mathrm{A}$ and $\mathrm{B}$. Therefore, protections $A$ and $B$ are informed of this fault. In this case, the relay of protection $B$ sends two logic signals; a tripping signal to its circuit-breaker and a logic wait signal to protection $\mathrm{A}$. The circuit-breaker $B$ opens after its delay time $t_{B}$ before protection $\mathrm{A}$ begin active. Knowing that protection $\mathrm{A}$ is locked by the wait logic signal. The simulation results of this case are shown is Figure 6.

(a). Output voltage of circuit-breaker A, (b). Current across circuit-breaker A, (c). Output voltage of circuitbreaker B, (d). Current across circuit-breaker B, (e). High frequency signal $U t$ transmitted by means of the transmitter coupler using PLC technique, (f). High frequency signal Ur received by means of the receiver coupler using PLC technique, (g). Tripping signal of circuit-breaker A, (h). Tripping signal of circuit-breaker 
B, (k). Logic wait signal transmitted from protection A to protection B via PLC system.

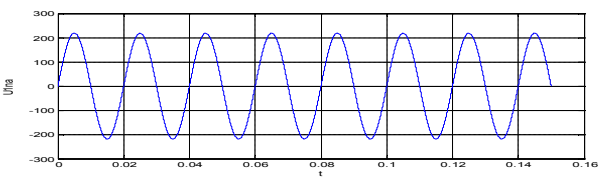

a

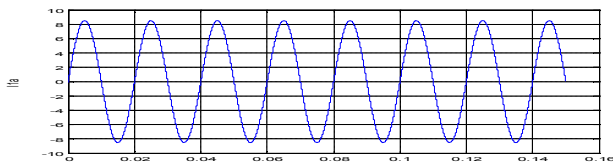

b
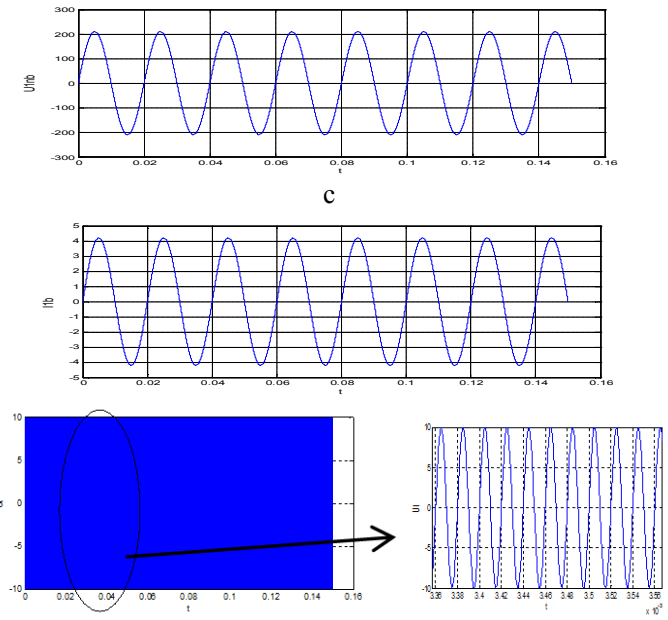

d
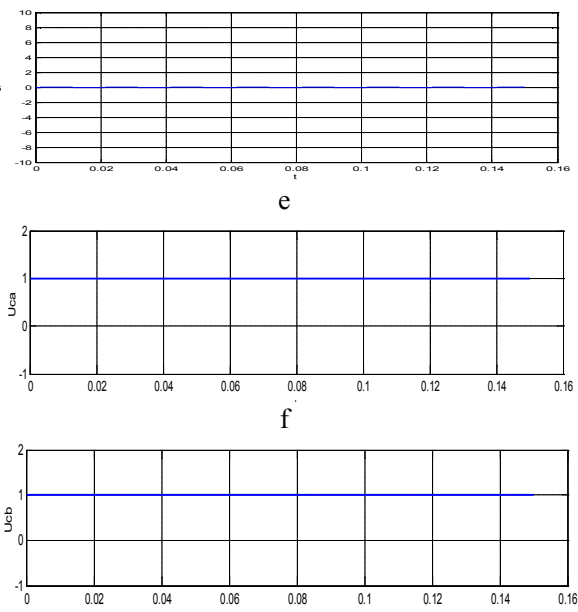

$\mathrm{g}$

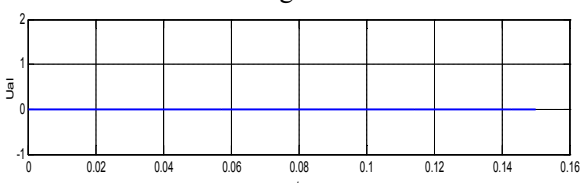

$\mathrm{k}$

Figure 5. Simulation results of case 1.
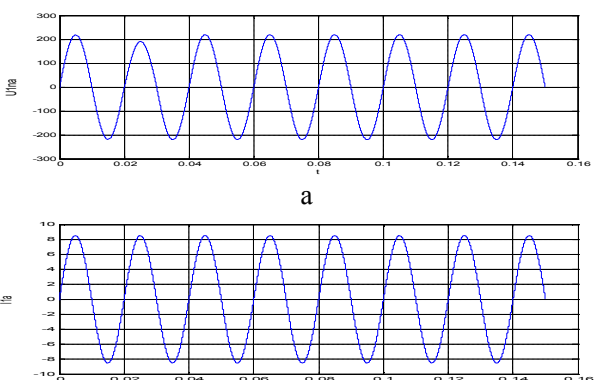

b
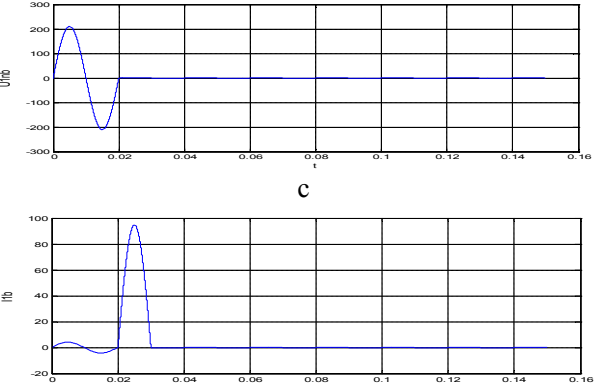

$\mathrm{d}^{\mathrm{t}}$

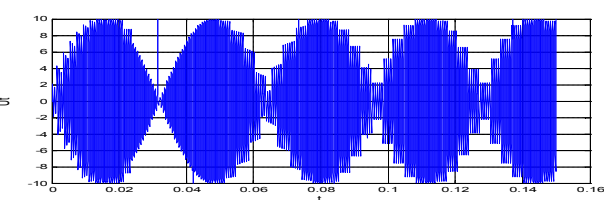

e

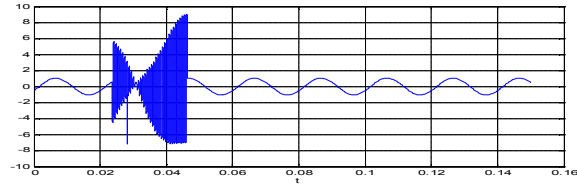

$\mathrm{f}$
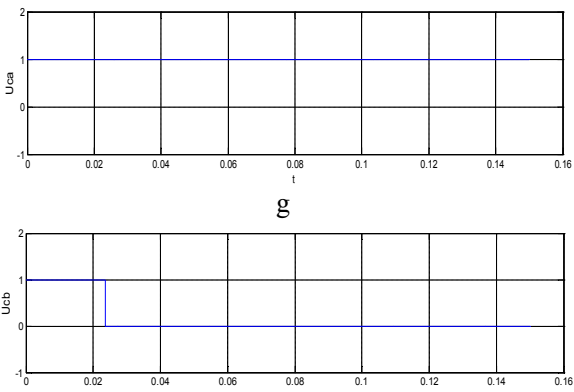

h

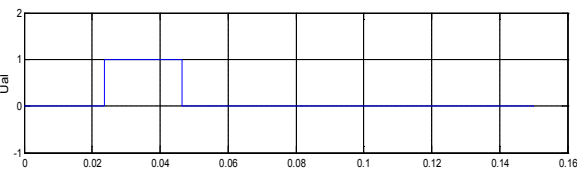

$\mathrm{k}$

Figure 6. Simulation results of case 2. 


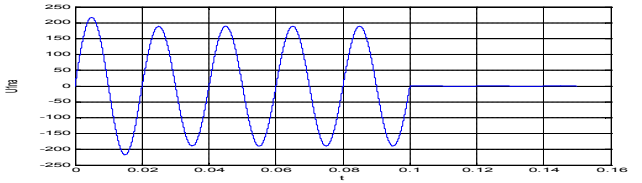

a

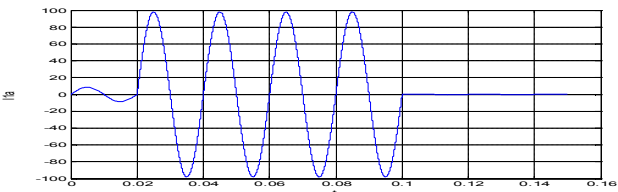

b

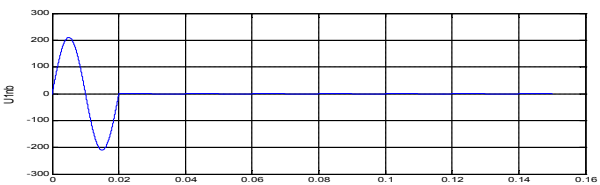

$\mathrm{c}$

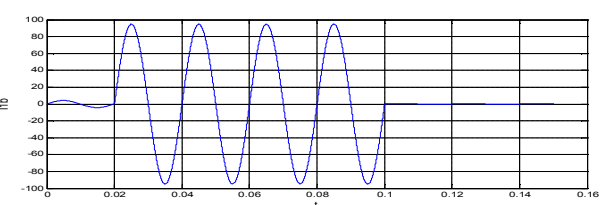

d

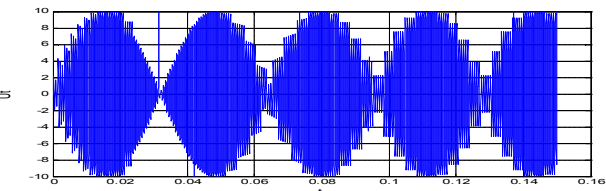

e

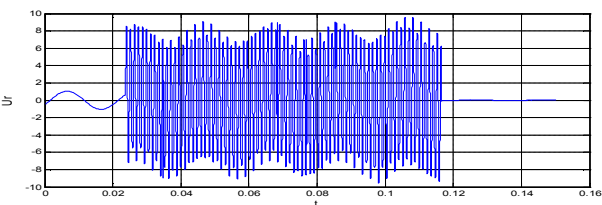

f

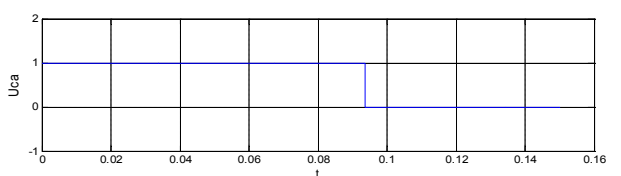

$\mathrm{g}$

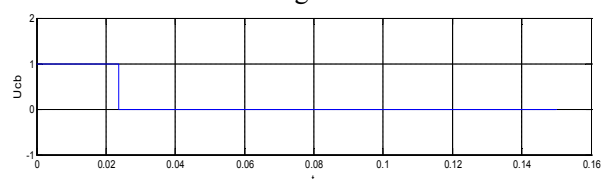

h

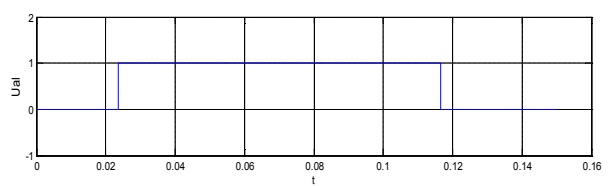

$\mathrm{k}$

Figure 7. Simulation results of case 3 .

Case 3- When a fault appears in point $M$ and protection $B$ is broken down:
Consider now that a fault appears in point $M$ and protection $\mathrm{B}$ is broken down. As the previous case, the fault current through both protections $\mathrm{A}$ and $\mathrm{B}$ which are informed of this fault. Hence, the relay of protection B sends two logic signals; a tripping signal to its circuitbreaker and a logic wait signal to protection A. Because the protection $\mathrm{B}$ is broken down, its circuit-breaker does not open and for this reason the logic wait signal becomes longer. The circuit-breaker A opens after its delay time $t_{A}$ $+t_{a l}\left(t_{a l}\right.$ is the waiting time of protection $A$ before its activation). The simulation results of this case are shown is Fig. 7.

\section{HF attenuation measurement}

The signal attenuation equation [6] is represented as the ratio of the received high frequency signal $(U r)$ in protection A to the transmitted high frequency signal ( $U t)$ from protection $\mathrm{B}$ :

$$
A v(d B)=20 \log \left(\frac{U r}{U t}\right)
$$

(1)

The attenuation characteristics of the signal versus cable resistance, cable inductance and frequency variation are presented in Fig.8, Fig.9 and Fig.10, respectively.

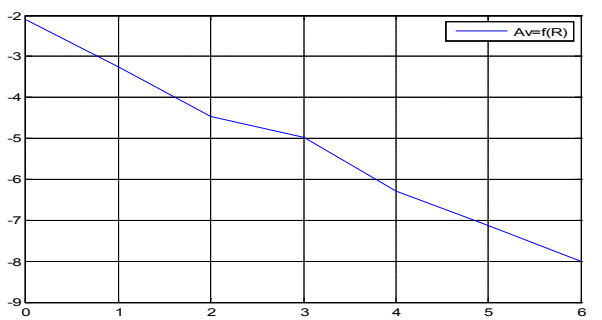

Figure 8 . HF signal attenuation versus line resistance variation.

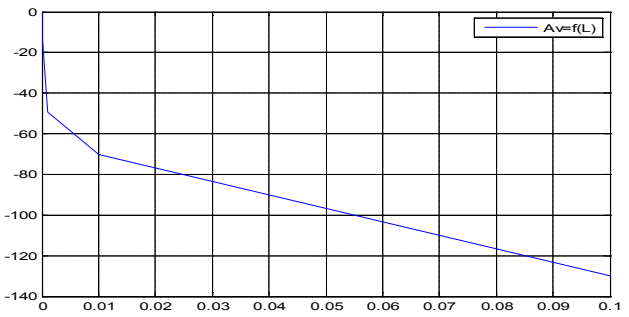

Figure 9. HF signal attenuation versus line inductance variation.

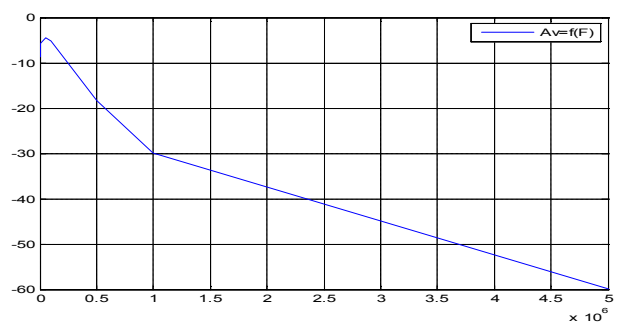

Figure 10. HF signal attenuation versus frequency variation. 


\section{Conclusion}

Electrical networks deliver electrical energy required for different consumers. However, the continuity of supply of receivers is sought from the network design. The main functions of protection are brought into play in order to ensure continuity of service. The most used function is the protections of the max current against defects in short-circuit. This work is concerned with the use of the function. In the case of a protection system with has many levels, different protection are linked to each other with a logic selectivity with a polite cable and CPL.

\section{Reference}

[1] F. Sautriau, Protection of electrical distribution networks the logic selectivity system, February 1983.

[2] Ali Reza Fereidouni, Hamed Nafisi, Mehdi Garmrudi, Hamed Hashemi Dezaki, The Effect of Distributed Generation in Distribution Network on Coordination of Protective Devices, International Review on Modelling and Simulations (I.RE.MO.S.), Vol. 4, N. 2011, pp. 17731780 .

[3] André Sastre, Network protection (HTA ) industrial and tertiary, CT 174 édition décembre 1994.

[4] Mohamad Haffar, Zeashan H Khan, Jean-Marc Thiriet, Eric Savary, An extension to IEC 61850 for solving selectivity problem in electrical substations, Author manuscript, published in "23rd IAR Workshop on Advanced Control and Diagnosis, Coventry : United Kingdom (2008)

[5] Eklas Hossain, Sheroz Khan, et Ahad Ali, Modeling Low Voltage Power Line as a Data Communication Channel, International Conference on Electrical Engineering (ICEE 2008), WCSET 2008: World Congress on Science, Engineering and Technology, Paris, France, 2008, pp. 2123 .

[6] Charles J. Kim, and Mohamed F. Chouikha E. F. Fuchs, Attenuation Characteristics of High Rate HomeNetworking PLC Signals, IEEE transactions on power delivery, vol. 17, 2002, pp. 945-950.

[7] I. Hakki Cavdar, et Engin Karadeniz, Measurements of Impedance and Attenuation at CENELEC Bands for Power Line Communications Systems, Sensors 2008, vol 8, pp. 8027-8036, DOI: 10.3390/s8128027.

[8] T. Tran-Anh, P.Aurio, T. Tran-Quoc IDEAl, Distribution network modeling for Power Line Communication applications, 0-7803-8844-5/05/\$20.00c2005 IEEE.

[9] P. Malathi et P.T.Vanathi, Power Line Communication using OFDM and OGA, AIML Journal, Vol 7, Issue (1), 2007.

[10] Yihe Guo, Zhiyuan Xie, and Yu Wang, A Model for 10kV Overhead Power Line Communication Channe, Huangshan , P. R.China, pp. 289-292. 